\title{
Numerical simulation of cutting layer in internal corners milling
}

\author{
JAN BUREK \\ RAFAŁ FLEJSZAR \\ BARBARA JAMUŁA *
}

Dr hab. inż. Jan Burek, prof. PRz, jburek@prz.edu.pl, https://orcid.org/0000-0003-2664-5248 - Katedra Technik Wytwarzania i Automatyzacji, Wydział Budowy Maszyn i Lotnictwa, Politechnika Rzeszowska, Rzeszów, Polska

Mgr inż. Rafał Flejszar, r.flejszar@prz.edu.pl, https://orcid.org/0000-0001-5231-6494 - Katedra Technik Wytwarzania i Automatyzacji, Wydział Budowy Maszyn i Lotnictwa, Politechnika Rzeszowska, Rzeszów, Polska

Mgr inż. Barbara Jamuła, b.jamula@prz.edu.pl, https://orcid.org/0000-0002-2743-4373 - Katedra Technik Wytwarzania i Automatyzacji, Wydział Budowy Maszyn i Lotnictwa, Politechnika Rzeszowska, Rzeszów, Polska

The analytical and numerical model of the cross-section of the machined layer in the process of milling of concave rounding is presented. Simulation tests were carried out to determine the cross-sectional area of the cutting layer. A strategy has been developed that allows to increase the stability of the crosssection area of the cutting layer when the mill enters the inner corner area.

KEYWORDS: concave corners, cutting layer analysis, machining strategies

\section{Introduction}

Thin-walled constructions are increasingly used in many industries, allowing the strength conditions to be maintained while reducing their weight. In the industrial production of this type of parts, a typical problem is the processing of areas of relatively large depth, the so-called pocket. This applies to both the selection of optimal technological process parameters and the appropriate machining strategy. When milling the inside corners of pockets, the cross-sectional area of the cutting layer clearly changes (fig. 1), which increases the cutting forces $[2,4-6]$.

Value of the cross-sectional area increases from the minimum value $\left(A_{1}\right)$ to the maximum value $\left(A_{3}\right)$ on the last fragment of the linear tool path segment (from point $P_{\min }$ to $P_{\max }$ ).

The change in cross-section starts when the tool outline exceeds the Pz point and reaches the maximum value when the tool axis is at the Pmax point. Value of the cross-sectional area remains constant during further machining of the rounding. Location of the points depends on the geometry: tool, workpiece and blank. The largest differences in the value of the cross-sectional area can be observed when the tool radius is close to the radius of the workpiece or when there is relatively large machining allowance. The consequence is the occurrence of vibrations, elastic, and even plastic deformations of the workpiece and tool, which affects the deterioration of dimensional accuracy $[1,3,7]$.

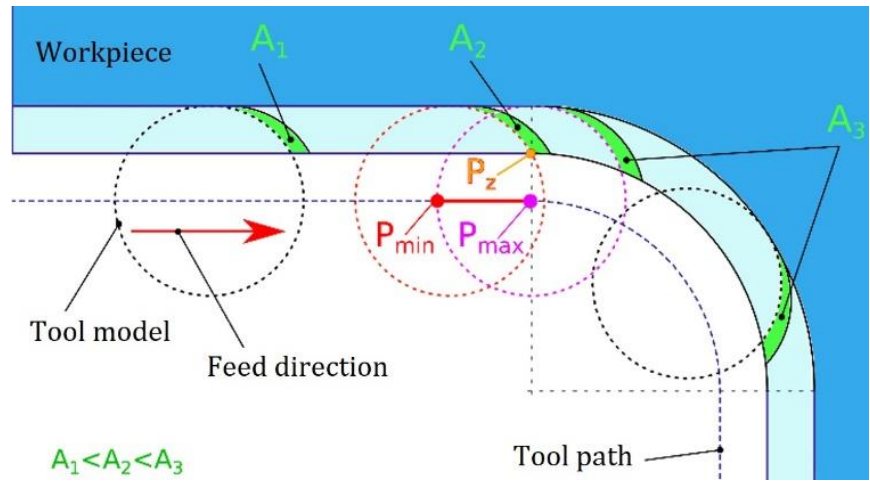

Fig. 1. Change of the cross-sectional area of the cutting layer $(A)$ during the milling cutter entering the concave corner area 
Tool manufacturers recommend finishing machining with milling cutters with smaller radius than that of the workpiece. There are also many programs and control system functions that allow the feedrate to be reduced in the concave rounding area. Feedrate optimization can be carried out according to the following criteria: constant wrap angle, constant volume of processed material or constant peripheral speed $[3,8,9]$.

\section{Mathematical model}

At the initial stage of creating the model:

- a two-dimensional cutter model for the circle was simplified,

- the corner in question was adopted in the second quarter of the coordinate system,

- cutter radii are limited to values less than or equal to the rounding radius values of the blank,

- the number of cutter blades was not considered,

- fixed cutting width was assumed.

An analysis of the milling entry into the concave rounding area was carried out. Individual curves were described by equations to determine the intersection points and the cross-sectional area of the cutting layer (fig. 2). During the process, the tool moves along the tool path, so it was necessary to perform the analysis for $n$ steps, where the iterative step equaled the value of the feedrate per revolution $f$.

As the tool position changes, the cross-sectional area of the cutting layer also changes. Mathematical analysis of the cross-sectional shape of the cutting layer was carried out and it was divided into several areas (fig. 3). This was due to the need to determine appropriate integration boundaries for calculating the area of the area bounded by four curves. A function that could be calculated numerically was adopted as a mathematical description of the surface area.

Numerical calculations were made in Matlab software version R2018b. A program was developed that allows for simulation of the cutting layer cross-section for given parameters $R_{1}, R_{3}, a_{\mathrm{e}}$ and $f$ - for both constant and variable feedrate.

To maintain a constant cross-sectional area of the cutting layer, it was necessary to change the parameters affecting the value of the field function. Due to constant technological assumptions - such as radius of the workpiece rounding, cutter diameter and cutting width - the only parameter that could be used to control the value of the cross-sectional area was the feedrate. The field function is not a function that depends only on the feedrate, but a function of many variables that are often dependent on each other. Therefore, it is not possible to provide an analytical formula for the cross-sectional area as a function of feedrate.

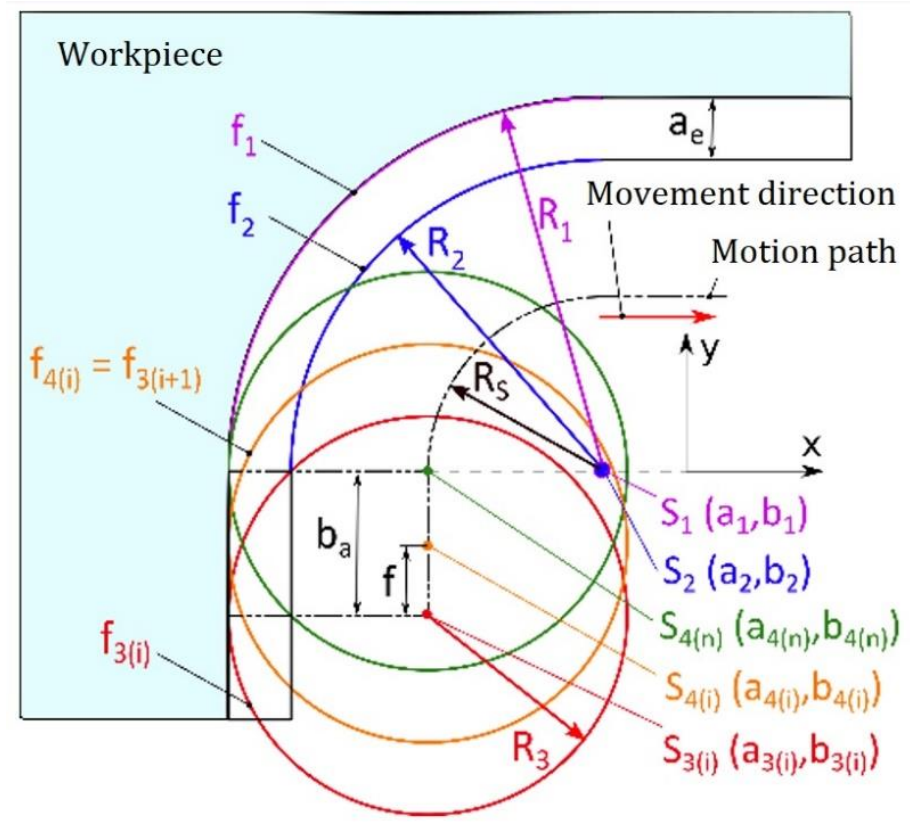

Fig. 2. Designations used in mathematical modeling: $R_{1}$ - rounding radius of the workpiece; $R_{2}$ - rounding radius of the blank; $R_{3}$ - tool rounding radius; $R_{s}$ - tool path rounding radius; $f$ - feedrate per revolution; $a_{\mathrm{e}}$ - cutting width; $S_{\mathrm{n}}$ - center of circle $n$ with coordinates $a_{\mathrm{n}}, b_{\mathrm{n}}$; $f_{n(i)}$ - mathematical function representing a circle with radius $R_{n}$ with a center at $S_{n}$; $b_{a}$ - coordinate of the tool's position relative to the start of the rounding 


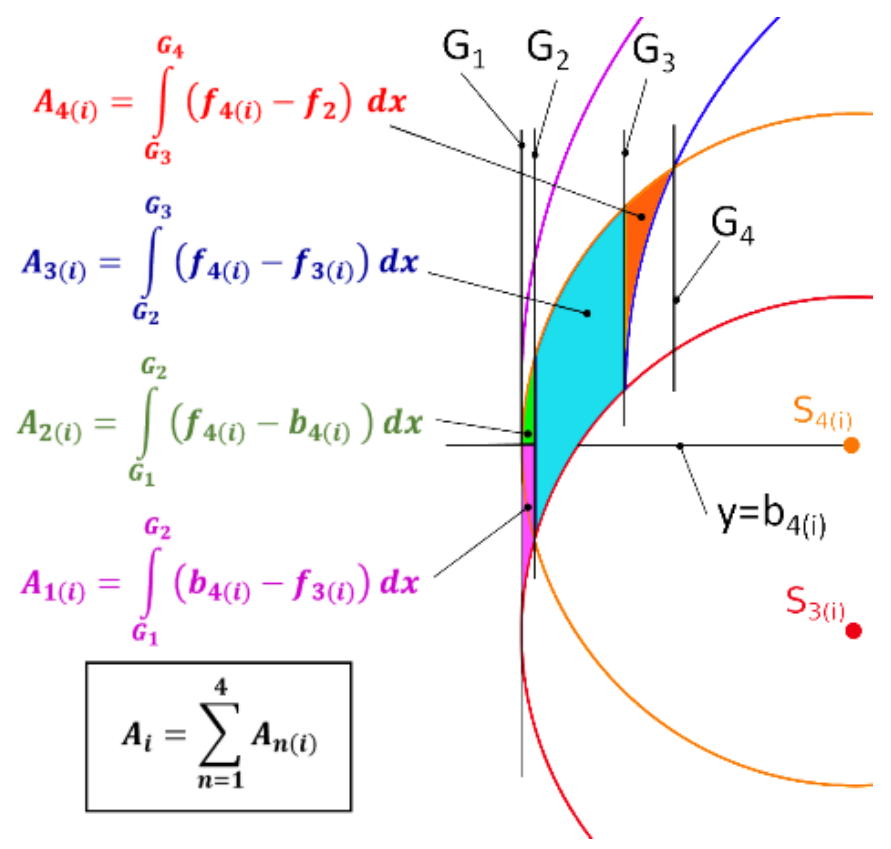

Fig. 3. Analytical description of the cross-sectional area of the cut layer: $A_{i}$ - cross-sectional area of the cutting layer during step $i$; $G_{n}$ - integration limits

\section{Numerical simulations}

In the functions describing the field, there are many variables, sometimes interdependent, therefore the surface area analysis was presented when one parameter was changed - for the other parameters, constant values were maintained $\left(f=0.15 \mathrm{~mm} / \mathrm{rev}, R_{1}=10 \mathrm{~mm}, R_{3}=5 \mathrm{~mm}, a_{\mathrm{e}}=1 \mathrm{~mm}\right.$ ) (fig. 4). Only fragment of the tool path was considered, where the surface area value changed. For $b_{\text {a }}$ values smaller and larger than those defined in the plot, the field has a fixed value.

a)

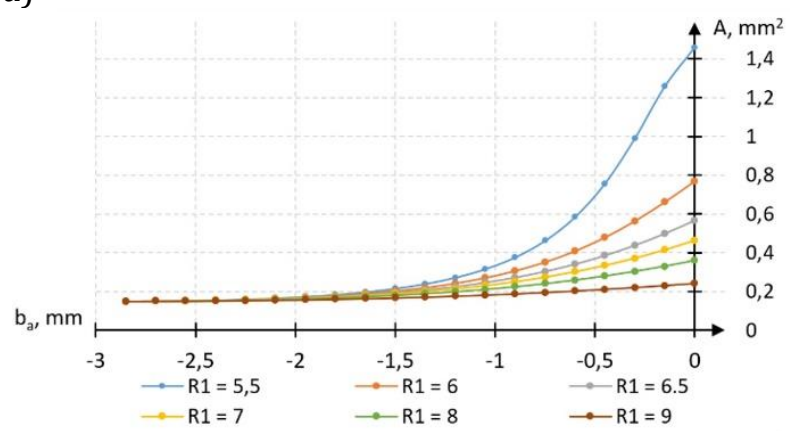

c)

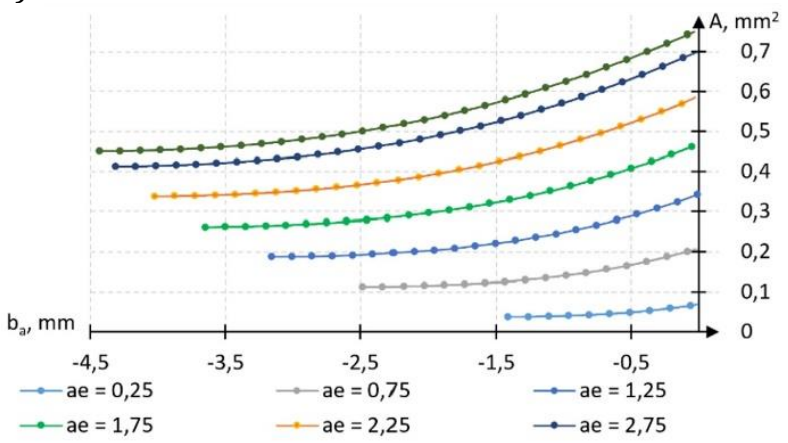

b)

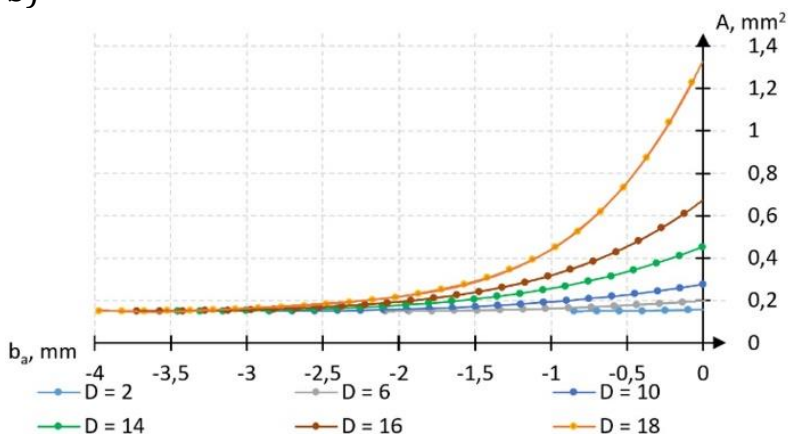

d)

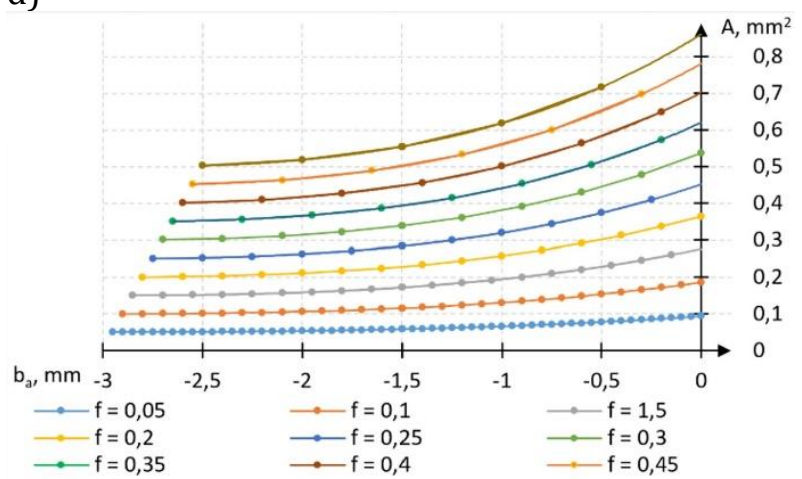

Fig. 4. Changes in the cross-sectional area of the cutting layer $A$ depending on the position of the tool relative to the beginning of the rounding $b_{\mathrm{a}}$ for variable values: a) rounding radius of the workpiece $R_{1}$, b) cutter diameter $\left.D, c\right)$ cutting width $a_{e}$, d) feedrate $f$ 
Performed simulations show that the change of parameters significantly affects the cross-sectional area of the machined layer. The most important role in the process is played by the rounding radii of the tool and the workpiece. The largest step changes can be observed for the tool radius specified as the upper limit of the test.

Value of the cross-sectional area for a cutter with a diameter of $18 \mathrm{~mm}$ when machining a $10 \mathrm{~mm}$ radius increased almost tenfold. In the analogous case, when a $16 \mathrm{~mm}$ diameter cutter is used, a five-fold increase in the measured size is visible, and for a tool with a diameter of $10 \mathrm{~mm}$ - only twice. As the diameter of the tool decreases, maximum value of the cross-sectional area of the cut layer can be observed. This confirms the thesis that the largest problem is machining elements with a small rounding radius with a large diameter milling cutter. In addition, both the cutting width and the feedrate determine the nominal value of the cross-sectional area, but their modifications influence the course of the function much more proportionally.

The course of the graphs suggests how feedrate corrections can be made. Most course of the field functions can be satisfactorily approximated with a parabola, but the most important ones (the cutter radius comparable to the workpiece radius) allow for more reliable approximation only with third or fourth degree polynomials. This information was used to designate the function that will modify the feedrate. An attempt was made to change the feedrate depending on several polynomial functions of different stages.

According to fig. 2, the tool enters the rounding area when it is on the tool path in position $b_{3(1)}$ (the feedrate value is $f$ ) and the cross-sectional area value reaches its maximum when $b_{\mathrm{a}}=0$ (the feedrate value should be $f_{\mathrm{k}}$ ). Therefore, the feedrate should be changed in this section.

Feedrate variability was assumed depending on several simple polynomial functions, selecting intermediate points, and then approximating the functions by the least squares method (fig. 5). The feedrate correction was carried out from the nominal value $f_{\mathrm{n}}$ to reach the final speed $f_{\mathrm{k}}$ - selected to maintain a constant peripheral speed of the milling cutter:

$$
f_{\mathrm{n}} \frac{R_{\mathrm{s}}}{R_{1}}=f_{\mathrm{k}}
$$

where: $f_{\mathrm{n}}$ - nominal feedrate per revolution; $R_{\mathrm{S}}$ - tool path rounding radius; $R_{1}$ - rounding radius of the workpiece; $f_{\mathrm{k}}$ - corrected feedrate per revolution, corresponding to the feedrate, for which the peripheral speed of the milling cutter is constant.

The field value was again analyzed after applying an algorithm modifying the feedrate for the tool diameter of $18 \mathrm{~mm}$ (fig. 6). A significant decrease in the value of the cross-sectional area of the cutting layer is visible for any feedrate reduction strategy. Depending on the feedrate correction function used, different results were obtained. It was assumed that the feedrate was corrected only to minimize the increase in cross-sectional area.

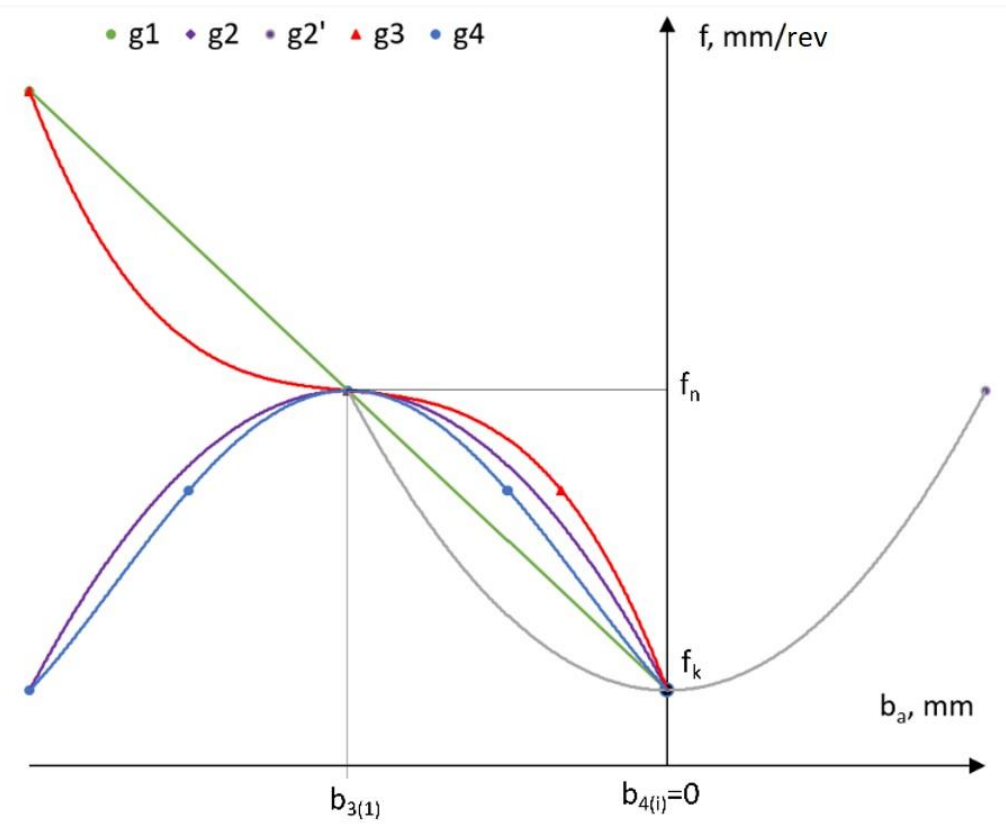

Fig. 5. Course of the function $g_{i}(i$ - polynomial degree) selected for feedrate correction from the nominal value $f_{\mathrm{n}}$ to the corrected $f_{\mathrm{k}}$ 


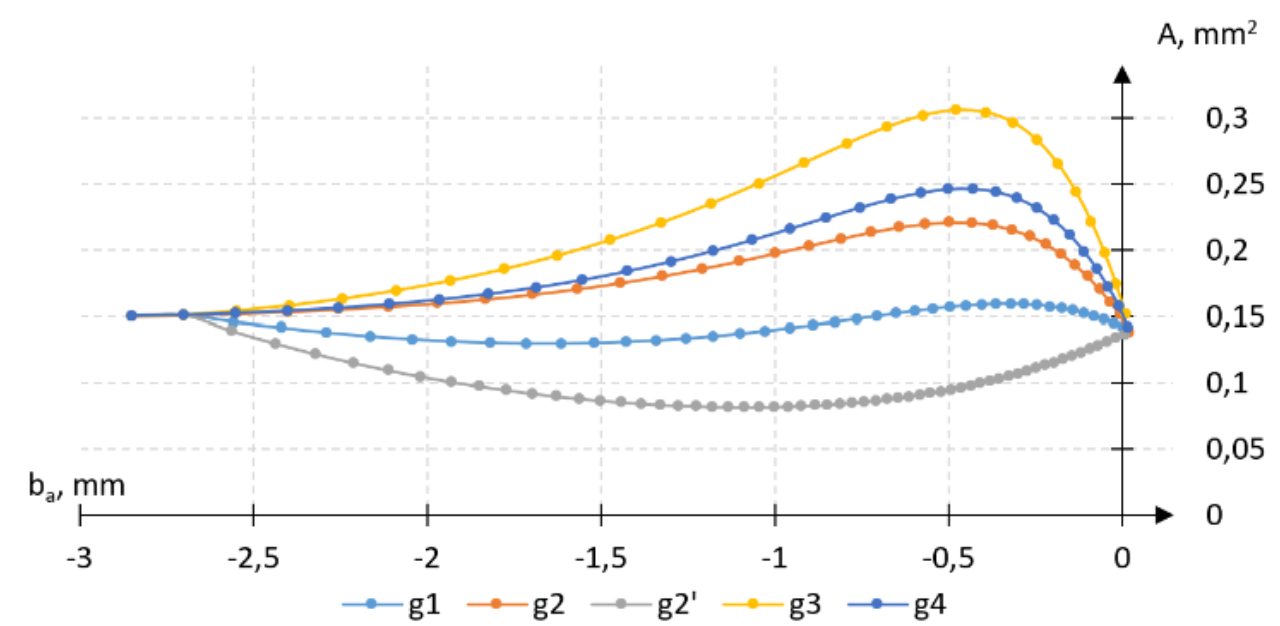

Fig. 6. Graph of changes in the cross-sectional area of the cutting layer $A$ depending on the position of the tool relative to the beginning of rounding $b_{a}$ after applying the feedrate correction for various correction functions $g$

Presented charts show that:

- the linear function allowed for the best stabilization of the cross-sectional area of the machined layer, however, for the most of machining process, the machined layer was smaller than the nominal;

- the $g 2$ quadratic function made it possible to reduce the maximum cross-sectional area value by a factor of four and shifted the extreme point of the field function;

- the use of higher order polynomials gave very similar effects, although not as good as those obtained when the quadratic function was applied;

- when determining the function, key points were the basis for approximation - the use of the square function $g 2$ ' compared to $g 2$ caused an excessively large decrease in the measured value.

\section{Conclusions}

Presented cutting layer analysis can be the basis for optimizing the feedrate value when the milling cutter enters the areas of concave rounding. Although the proposed strategy is characterized by many simplifications, it allows to increase the stability of the cross-sectional area of the machined layer. The choice of the best strategy depends on the requirements imposed and errors occurring during machining. It is worth noting that if it is possible for the cross-section of the cutting layer to be smaller than the nominal one, the best stability can be obtained, however, this choice is associated with longer machining time, which in turn significantly reduces the productivity.

\section{REFERENCES}

[1] Arif M., Rahman M., San WY. "Analytical model to determine the critical feed per Edg for ductile-brittle transition In milling process of brittle materials". International Journal of Machine Tools \& Manufacture. 51 (2011): 170-181.

[2] Baohai W., Xue Y., Ming L., Ge G. "Cutting force prediction for circular end milling proces”. Chinese Journal of Aeronautics. 26 (2013): 1057-1063.

[3] Burek J., Flejszar R. „Analiza warstwy skrawanej w obróbce elementów cienkościennych o złożonej geometrii". Mechanik. 8-9 (2018). 778-780.

[4] Han X., Tang L. "Precise prediction of forces in milling circular corners". International Journal of Machine Tools and Manufacture. 88 (2015): 184-193.

[5] Kuczmaszewski J., Pieśko P., Doluk E. „Obróbka naroży wewnętrznych o małym promieniu zaokrąglenia”. Mechanik. 5-6 (2017): 418-420.

[6] Shixiong W.U., Bin Li., Wei Ma. "Research on cutting force of corner milling of inclined plane". Key Engineering Materials. 693 (2016): 856-862.

[7] Yue C., Liu X., Ding Y., Liang S.Y. "Off-line error compensation in corner milling process". Journal of Engineering Manufacture. 232, (2016): 1172-1181.

[8] Sandvik Coromant. „Milling - good practice. Setting solid foundations” Application Guide (2015).

[9] Documentation: NX 11. 